\title{
Highly Sensitive and Indirect Electrochemical Sensing of Ascorbic Acid Based on the Catalytic Oxidation of Glucose on the Ni Nanoparticles-ionic Liquid Composite
}

\author{
Jie Yang ${ }^{1}$, Weijuan $\mathrm{Li}^{2}$, Tao Yang ${ }^{2}$, Shifeng $\mathrm{Hou}^{3, *}$ \\ ${ }^{1}$ Bio-nanotechnology \& Medical Engineering Institute, Jining Medical College, Jining, 272067, P. R. \\ China \\ ${ }^{2}$ College of Chemistry and Molecular Engineering, Qingdao University of Science and Technology, \\ Qingdao, 266042, P. R.China \\ ${ }^{3}$ Chemistry and Biochemistry Department,Montclair State University, New Jersey, 07043, US \\ *E-mail: yangjiequst@126.com
}

doi: $10.20964 / 2016.07 .12$

Received: 30 November 2015 / Accepted: 25 April 2016 / Published: 4 June 2016

In this system, a $\mathrm{Ni}$ nanoparticle-ionic liquid platform $\left(\mathrm{Ni}_{\mathrm{NP}}-\mathrm{IL}\right)$ was developed for synergistical and indirect determination of ascorbic acid (AA) via electrocatalytic recycle between $\mathrm{Ni}$ and glucose. The $\mathrm{Ni}_{\mathrm{NP}}$-IL film was characterized by scanning electron microscope and cyclic voltammetry. The activation of $\mathrm{Ni}_{\mathrm{NP}}-\mathrm{IL} / \mathrm{CPE}$ in alkaline media, forming a $\mathrm{Ni}(\mathrm{OH})_{2} / \mathrm{NiO}(\mathrm{OH})-\mathrm{IL}$ film, was found to induce the adsorption of AA at the electrode surface. Based on the electrocatalytic oxidation of glucose at the activated $\mathrm{Ni}_{\mathrm{NP}}-\mathrm{IL} / \mathrm{CPE}$ in $0.08 \mathrm{~mol} / \mathrm{L} \mathrm{NaOH}$ solution, a novel detection strategy was constructed for indirect determination of AA. Under optimal conditions, AA was amperometrically determined by using the as-prepared $\mathrm{Ni}_{\mathrm{NP}} \mathrm{IL} / \mathrm{CPE}$ with a detection limit of $4.5 \times 10^{-8} \mathrm{~mol} / \mathrm{L}(\mathrm{S} / \mathrm{N}=3)$. Possible interferences from the coexisting ions were also investigated The results indicated that the designed biosensor could be used for the detection of AA in the presence of dopamine, borate, nitrate, chloride, acetate and carbonate ions.

Keywords: Ni nanoparticles, ionic liquid, glucose, ascorbic acid, indirectly determination.

\section{FULL TEXT}

(C) 2016 The Authors. Published by ESG (www.electrochemsci.org). This article is an open access article distributed under the terms and conditions of the Creative Commons Attribution license (http://creativecommons.org/licenses/by/4.0/). 